strains. Measurement of the amount of penicillinase formed by a culture by such methods as that of K. G. H. Dyke and colleagues $^{7}$ is not a procedure which can be expected of a clinical laboratory. Perhaps the simplest effectual method is a tube-dilution test with both a small and a large inoculum. The therapeutic problem can be solved if a severe staphylococcal infection is accepted as an indication for combined treatment. Mixtures of antibiotics have been used for many unsuitable purposes, but one undeniable indication for them is to attack a micro-organism insufficiently susceptible to any single drug. The degree of susceptibility required for treating endocarditis is greater than in most diseases, and indeed of a different quality, since treatment will not succeed unless it actually sterilizes the lesion. It has long been recognized that Streptococcus faecalis endocarditis will usually respond only to treatment with two bactericidal antibiotics acting synergically, either penicillin with streptomycin, or penicillin with one of the other aminoglycosides (streptomycin, neomycin, kanamycin, and others). ${ }^{8}$ Should not a staphylococcal endocarditis be regarded in the same light ?

Burgess and Evans had themselves ascertained, though their patient died before they could act on the information, that a combination of either streptomycin or kanamycin with cephaloridine was bactericidal for her atrain of staphylococcus. Last week's issue of the B.M.F. contains the report of a clinicopathological conference on a case of staphylococcal endocarditis which failed to respond to methicillin and other penicillins. When the strain was re-examined long after the patient's death, methicillin combined with either streptomycin or kanamycin was found to be totally bactericidal. R. J. Bulger, ${ }^{10}$ examining nine strains of methicillin-resistant staphylococci, including the "Seattle" strain which had caused a fatal infection despite treatment with cephalothin, found that a combination of kanamycin with either cephalothin or methicillin was strongly synergic. He goes so far as to advise that treatment with such a combination should be instituted at once, even before its action has been tested in the laboratory. The position may therefore be, not simply that cephaloridine is inadequate for treating some of these infections, but that some of them cannot be treated successfully with any single antibiotic. Combined treatment should certainly be actively considered, if not immediately instituted, for any patient with acute staphylococcal endocarditis. It may also be worth considering for the less severe infections, often caused by less virulent organisms, which sometimes follow intracardiac surgery. It is essential that the laboratory should carry out tests of the bactericidal action (not merely of the capacity to inhibit growth) of single antibiotics and of a few promising combinations. The significance of results so obtained is indisputable, and the necessity for such work is so uncommon that the extra effort should not be grudged. This is a situation in which the laboratory can contribute directly to the saving of life.

1 Burgess, H. A., and Evans, R. J., Brit. med. F., 1966, 2, 1244.

2 Foord, R. D., and Snell, E. E., ibid., 1966, 2, 1656.

3 Benner, E. J., Bennett, J. V., Brodie, J. L., and Kirby, W. M. M., f. Bact., 1965, 90, 1599 .

- Ridley, M., and Phillips, I., Nature (Lond.), 1965, 208, 1076.

- Muggleton, P. W., O'Callaghan, C. H., and Stevens, W. K., Brit. med. f., 1964, 2, 1234.

- Murdoch, J. McC., Spiers, C. F., Geddes, A. M., and Wallace, E. T., ibid., 1964, 2, 1238.

' Dyke, K. G. H., Jevons, M. P., and Parker, M. T., Lancet, 1966, 2, 835.

- Garrod, L. P., and Waterworth, P. M., F. clin. Path., 1962, 15, 328.

- Brit. med. F., 1967, 1, 479.

10 Bulger, R. J., Lancet, 1967, 1, 17.

\section{Antilymphocyte Serum}

At present most workers in the field of transplantation rely on the use of drugs such as azathioprine and prednisone to overcome the immunological reaction which may lead to rejection of the graft. Another way of tackling this problem might be to use an antiserum against lymphocytes, which are thought to be concerned in the process of rejection. Such a serum was first used in 1899 by E. Metchnikoff, ${ }^{1}$ who produced it by injecting cells from the lymph nodes of rabbits into guinea-pigs. Metchnikoff found that immune serum produced by the guinea-pigs was capable of agglutinating and destroying the white blood cells of rabbits. In the 50 years after Metchnikoff's experiments there were only a few reports of further investigations with antilymphocyte serum, but in the past few years the rapid increase of work on tissue transplantation has re-aroused interest in the subject. In 1960 M. F. A. Woodruff ${ }^{2}$ produced an anti-rat lymphocyte serum in rabbits, which within two hours of injection into rats was found to lower considerably the number of lymphocytes in the circulation. Despite daily injections of the serum, however, the survival of homografts of the skin, ovary, and adrenal was not prolonged, and the number of circulating lymphocytes had returned to normal by the tenth day.

R. H. Levey and P. B. Medawar ${ }^{3}$ have recently shown that an antilymphocyte serum prepared in rabbits against the cells of the thymus from mice was an extremely effective immunosuppressive agent, which sometimes prolonged the survival of skin grafts indefinitely. The serum also inhibited the rejection of a second skin graft in animals, and prolonged the survival of grafts taken from unrelated strains of mice and even from other species. This observation contrasted with the findings with all other immunosuppressive agents-which are much more effective when there is a close relationship between donor and host. Initially Levey and Medawar considered that the serum might act by coating the lymphocytes and "blindfolding" them-since the action of the serum on prolonged graft survival did not appear to be related to the degree of lymphopenia. They now feel, however, that the antilymphocyte serum may act by preventing lymphoid cells from taking part in normal immune reactions. This action, they suggested, could be called "sterile activation," and it is entirely non-specific. Levey and Medawar have also shown that cortisone potentiates the immunosuppressive effect of antilymphocyte serum.

Two recent reports have dealt with the use of antilymphocyte serum for prolonging the survival of kidney transplants in animals. H. M. Abaza and his colleagues ${ }^{5}$ and J. G. Gray ${ }^{6}$ and his colleagues have both demonstrated a definite immunosuppressive action of anti-dog lymphocyte serum prepared in horses when this was injected into dogs which had received kidney homografts. In both cases the results were comparable to the effect of azathioprine (Imuran), though unfortunately-as with azathioprineAbaza and his co-workers found a high incidence of infection in the treated animals.

Metchnikoff, E., Ann. Inst. Pasteur, 1899, 13, 737.

2 Woodruff, M. F. A., The Transplantation of Tissues and Organs, 1960. Springfield, Ill.

s Levey, R. H., and Medawar, P. B., Ann. N.Y. Acad. Sci., in press.

- Proc. Nat. Acad. Sci., in press.

- Abaza, H. M., Nolan, B., Watt, J. G., and Woodruf, M. F. A., Transplantation, 1966, 4, 618.

' Gray, J. G., Monaco, A. P., Wood, M. L., and Russell, P. S., J. Immunol., 1966, 96, 217. 
At present there are conflicting opinions about how the most efficacious serum can be produced and also how it should be given. Some authors feel that it is essential to give the antilymphocyte serum before grafting ; others think that it is more effective if it is given shortly afterwards. There is a similar debate about how long treatment with antilymphocyte serum must be continued after the grafting operation in order to maintain the immunosuppressive effect. There is also marked species difference, and the most potent serum so far produced is that of the rabbit against the mouse. It is not yet known which species will produce the best sera for therapeutic use in man. There is a great deal of work to be done before we will know the full potentialities of antilymphocyte serum in the fields of both transplantation and autoimmune disease. In particular it is likely that attempts will be made to produce purified active fractions of the serum, since these seem less likely to give rise to dangerous allergic side-effects.

\section{Transfer of Tumour Cells by Mosquitoes}

Until a few years ago the suggestion that'mosquitoes might transmit cancer would have been treated with scepticism. But now there is a suspicion that certain species may transmit the virus or viruses thought to cause Burkitt's lymphoma. ${ }^{12}$ Moreover, W. G. Banfield and his colleagues ${ }^{2} 3$ have shown that mosquitoes can also transmit a lymphoma in experimental animals. The mechanisms are of considerable interest, particularly as they appear to be radically different from those believed to operate in the Burkitt tumour.

These experimental studies were carried out on a reticulum cell sarcoma which originally occurred as a single, apparently spontaneous, neoplasm in an old hamster. ${ }^{4}$ This tumour is readily transplanted by conventional techniques, grows rapidly at the site of transplantation, and metastasizes widely, with a late leukaemic phase. Mosquitoes (Aëdes aegypti) allowed to feed on animals during the leukaemic stage proved capable of transferring the lymphoma to normal hamsters. ${ }^{2}{ }^{3}$

Two techniques were employed to demonstrate this. In the first, mosquitoes in the post-prandial state were placed subcutaneously in normal animals and then crushed; in the second, the mosquitoes were allowed to bite the recipient animals. Although the incidence of positive "takes" was much lower by the latter method (10\% as opposed to $88 \%$ ), both groups showed one remarkable feature-the tumour was still transmissible for up to eight hours after the mosquito had fed. In all instances in which the tumour was successfully transferred the clinical course of the disease was indistinguishable from that observed in the original donor animals.

These are intriguing observations, but many features are still obscure. The role of the mosquito is probably purely passive and the actual species may be irrelevant. Nevertheless, it seems desirable to check this point by comparing the

\footnotetext{
Stanley, N. F., Lancet, 1966, 1, 961.

- Banfield, W. G., Woke, P. A., MacKay, C. M., and Cooper, H. L.,

- Science, 1965, 148, 1239. Cancer (Philad.), 1966, 19, 1333.

- Brindley, D. C., and Banfield, W. G., F. nat. Cancer Inst., 1961, 26, 949.

- Clements, A. N., The Physiology of Mosquitoes, 1963. Oxford.

- Cooper, H. L., MacKay, C. M., and Banfield, W. G., ₹. nat. Cancer Inst., 1964, 33, 691.

- Macpherson, I., ibid., 1963, 30, 795.

- Cooper, H. L., and Black, P. H., ibid., 30, 1015.
}

performance of a number of different species. Next, there is the apparent resistance of reticulum cell sarcoma cells to mechanical and chemical damage during their sojourn in the mosquito. Their distribution is uncertain, but they are clearly not confined to the mouth parts and proximal portions of the foregut. Some lymphoma cells may accumulate in the dorsal and ventral diverticula, but Banfield and his colleagues described large numbers of tumour cells in the midgut, ${ }^{3}$ the main site of secretion of digestive enzymes. ${ }^{5}$ Unless the tumour cells are unusually resistant to these enzymes many must surely be destroyed. This implies that successful "takes" can be achieved by the transference of relatively few viable tumour cells, but more information on this point, using standard quantitative transplantation methods, is clearly needed. On the other hand, there are grounds for supposing that the tumour cells are indeed unusually robust, in so far as the tumour has apparently been successfully transmitted between hamsters by simple feeding. ${ }^{4}$ Confirmation of this remarkable finding would seem to be desirable, preferably combined with some in-vitro studies on the cells, in an attempt to clarify the nature of their extraordinary resistance.

The exact sequence of events which takes place when mosquitoes bite the hamsters is obscure. It is not clear, for example, whether tumour cells are transferred in the saliva or whether viable cells are also regurgitated from lower down the gut, particularly from the foregut diverticula. Finally, there is the problem of what exactly is transmitted-tumour cells only, a virus only, or tumour cells plus virus? No tumours have been induced with a wide range of cell-free filtrates, ${ }^{4}$ and the authors emphasize the unusually consistent karyotype shown by the tumour ${ }^{6}$; seven extra chromosomes are regularly present, including a distinctive marker chromosome. This is in contrast to the more unstable karyotype patterns seen in cells transformed by viruses such as SV $40^{7}$ and polyoma. ${ }^{8}$ These facts support the view that transference was by cells in the present experiments, but they do not exclude the possibility that the reticulum cell tumour was originally induced by a virus.

Though much remains to be clarified, it appears that in certain circumstances the mosquito may transmit enough viable tumour cells to healthy recipients to induce tumours in them. But undoubtedly the lymphoma used by Banfield and his colleagues is highly unusual and the relevance of their findings to the transmission of the Burkitt tumour and other human cancers cannot yet be assessed. Further information will be awaited with interest.

\section{Improving Medical Communication}

In recent years the American National Library of Medicine, at Bethesda in Maryland, has contributed greatly to the development and improvement of communication in the biomedical sciences. Foremost among these developments has been the introduction, in 1963, of the Medical Literature Analysis and Retrieval System (MEDLARS). ${ }^{1}$

This computerized system for the retrieval of information has two main purposes. Firstly, it makes the production of the Index Medicus easier, and, secondly, it provides a speedy

\footnotetext{
1 Rannie, I., Brit. med. F., 1966, 1, 1351.

2 Moll, W., Bull. med. Libr. Ass., 1966, 54, 456.

3 National Library of Medicine. Annual Report for the Fiscal Year 1965, 1966. Washington.

- f. Amer. med. Ass., 1965, 194, Adv. p. 21.

- Brit. med. F., 1966, 2, 67.
} 